\title{
Comparison of Body Image Perception of Young Women in the United States and Korea: From the National Health and Nutrition Examination Survey of the Two Countries
}

\author{
Yoon-Sook Kim \\ Konkuk University Medical Centre \\ Jin Kook Kim \\ Konkuk University Medical Centre \\ Jae Hoon Cho ( $\square$ jaehoon@kuh.ac.kr) \\ Konkuk University Medical Centre
}

\section{Research Article}

Keywords: body image perception, young women, United States, Korea

Posted Date: March 7th, 2022

DOI: https://doi.org/10.21203/rs.3.rs-1400803/v1

License: (1) This work is licensed under a Creative Commons Attribution 4.0 International License. Read Full License 


\section{Abstract \\ Background}

The purpose of this study is to investigate the differences in body image perception between young women in the United States and Korea.

\section{Methods}

This was a longitudinal study conducted using data from young women aged between 20 and 40 who participated in the National Health and Nutrition Examination Survey (1999-2018) of the US and Korea. "Overweight" body image perception with normal body weight was considered underestimation. Overweight or obesity with a "normal weight" or "underweight" body image perception is considered as overestimating.

\section{Results}

The percentage of young women who were overweight or obese was about $60 \%$ in the US and about $20 \%$ in Korea. Twenty years ago, the percentage of young women who overestimated their weight in the US was $30.3 \%$, before steadily declining. In Korea, it was $25.8 \%$ before rising to more than $41.9 \%$ in 2008 . Of the overweight women, $32.6 \%$ in the US and $15.7 \%$ in Korea underestimated their weight 20 years ago, but since then, the percentage has gradually increased in the US and declined in Korea.

\section{Conclusions}

Body image perception differed according to marital status and race. Young women in the US tend to underestimate their weight while in Korea they tend to overestimate it.

\section{Background}

The standard of physical beauty varies greatly between times and regions. In Korea, with its rapid westernization, there has been a big change, particularly noticeable for women's beauty. In the past, Korean women preferred round faces and chubby bodies, but today, long legs and slim bodies are increasingly favored [1, 2]. Moreover, Korean women are often dissatisfied with their own appearance, being very sensitive to others' evaluations of it [3]. This phenomenon is common in the modern society and has been reported not only in overweight women, but also in normal-weight ones [4]. In more severe cases, women distort their body image and diet excessively, leading to a variety of health issues, including depression, eating disorders, malnutrition, decreased physical activity, and reduced sleep time $[5,6]$. Therefore, having a healthy and sensible body image perception is very important.

However, it has been reported that body image perception does not necessarily correspond to the actual degree of obesity in many people. In other words, even people with normal weight may think of themselves as overweight or obese. Conversely, people who are overweight or obese sometimes perceive themselves as having normal weight [7]. This discrepancy between body image perception and the actual degree of obesity is more pronounced specifically in young women [8].

Body image perception is influenced not only by individual characteristics but also by cultural background [9]. Western societies value independent individuals, and people are do not necessarily consider others' judgement of them. Thus, body image perception is generally positive and tolerant to obesity. On the other hand, in the Asian society, relationships with others are very important, and people pay great attention to the evaluation of others. As a result, they tend to be more rigorous and negative about body image perception, so obesity is not well-tolerated $[10,11]$. This partially explains why the obese population is rapidly increasing in Western societies compared to Asian ones. It is well-known that obesity is also affected by gender, race, age, marital status, occupation, and income [7, 12, 13].

Despite the importance of cultural differences in body image recognition, few studies have attempted to directly compare Western and Asian communities. In addition, there have been few longitudinal studies observing the changes in time. In this study, we compared the changes in body image perception of young women in Korea and the United States over 20 years. This study intends to help young women form a correct body image perception and lead a healthy lifestyle, both physically and mentally.

\section{Methods Subjects}


This study was conducted using data from young women aged between 20 and 40 who participated in the Korean National Health and Nutrition Examination Survey (KNHANES, from 2001 to 2018, six sessions in total) and the National Health and Nutrition Examination Survey (NHANES, from 1999 to 2018, 10 sessions). The KNHANES is a program of studies designed to assess the health and nutritional status of adults and children in Korea. It is very similar in research goals, methods, measurement methods, and questionnaire items to the NHANES, allowing comparative studies between Korea and the US in various ways.

A total of 14,949 Korean young women were selected out of the 169,632 KNHANES participants, after excluding 10,518 individuals with missing weight history or BMI data. Regarding the US subjects, a total of 9,928 young women were selected from the 101,316 NHANES participants, after excluding 608 individuals. Data were collected and analyzed each session to examine the changes over time. All selection processes are presented in Fig. 1.

\section{Obesity grading}

Korea generally assesses the degree of obesity using the World Health Organization Asia-Pacific BMI classification. However, in this study, the WHO BMI classification was used to compare obesity prevalence and body image between Korea and the US under the same conditions. If the $\mathrm{BMI}$ is less than 18.5, it is defined as underweight; between 18.5 and 25 is defined as normal weight; more than 25 and less than 30 is overweight, and over 30 is defined as obesity.

\section{Body image perception}

In both the KNHANES and the NHANES, the body image perception question was "How do you consider your weight?". The responses in the NHANES were "overweight," "underweight," or "about the right weight." Selecting "refused" or "don't know" is considered as missing data. The KNHANES' responses are further divided into "very overweight," "slightly overweight," "normal weight," "slightly underweight," or "very underweight." To compare the two studies, "very overweight" and "slightly overweight" were classified as "overweight," and "slightly underweight" and "very underweight" were classified as "underweight." "About the right weight" was considered the same as "normal weight." Demographic data

We collected demographic data already proven as related to body image perception, including educational level (college graduate / or not), marital status (never married / or not), occupation (professional or managerial occupation / or not), and race (Hispanic, White, Black, or Asian). To reflect the current situation, only the most recent sessions of the KNHANES (2016-2018) and the NHANES (2017-2018) were used.

\section{Statistical analysis}

We created a $3 \times 4$ cross table for each session (see in Supplement). Body image perceptions ("underweight," "right weight," and "overweight") are arranged in the columns, and BMI classifications ("underweight," "normal weight," "overweight," and "obesity") in the rows. Using this cross table, the following four items were calculated for each session:

1. The percentage of young women who are overweight and obese according to the BMI classification.

2. The percentage of young women who are in the normal BMI range but consider themselves as overweight.

3. The percentage of young women who are overweight but consider themselves as normal or underweight;

4. The proportion of young women who are obese but consider themselves as normal or underweight.

The above results are presented as a dotted graph, and a second-order polynomial trend line is inserted. Detailed numerical data are provided in the supplementary material. We did not conduct a trend analysis to see the differences between the two countries because the session intervals of the two studies were different, and thought that it was enough to show the trend of change. Only the latest sessions from the KNHANES (2016-2018) and the NHANES (2017-2018) were used for the subgroup analysis of education, marital status, occupation, and race, and the chi-square test was used for statistical analysis. SPSS (IBM SPSS version 25, Armonk, NY) was used for data cleanup and statistical analysis, and Excel (Microsoft Excel version 2016, Redmond, WA) was used for data analysis.

\section{Results}

\section{Young women who are overweight or obese over time}

The percentage of overweight and obesity among young women in the US was over 60\% in 1999-2000, remaining similar until $2017-2018$. In Korea, it was a little less than 20\% in 2001, and, like in the US, it remained similar until 2016-2018 (Fig. 2 A).

Young women in the normal BMI range who overestimate their body image 
In 1999-2000 in the US, 30.3\% of normal-weight young women rated themselves as overweight. However, this percentage steadily declined, dropping to $12.7 \%$ in $2017-2018$. In 2001 , this percentage was similar, around $26 \%$, in both the US and Korea, but since then it has steadily increased in Korea, exceeding $40 \%$ by $2007-2009$. It has gradually decreased afterwards, but in $2016-2018$ it was still $35.6 \%$, much higher than in the US (Fig. 2B).

\section{Overweight young women who underestimate their body image}

In the US, in 1999-2000, 32.6\% of overweight young women rated themselves as normal or underweight. However, this percentage has increased steadily, reaching $46.4 \%$ in $2017-2018$. In Korea, on the other hand, this percentage was $15.7 \%$ in 2001 , steadily decreasing since then to $2.8 \%$ in 2016-2018 (Fig. 2C).

\section{Obese young women who underestimate their body image}

In 1999-2000 in the US, about $12.6 \%$ of overweight young women rated themselves as normal or underweight. This percentage seemed to decrease slightly but has recently increased again. In Korea, it was 6.3\% in 2001, steadily decreasing to less than 1\% in 2016-2018 (Fig. 2D). Subgroup Analysis for the US

There was no significant difference in body image perception according to marital status or educational level among young women in the US. However, we found some differences between races. Hispanic and Black young women tended to underestimate body image perception while White and Asian ones were likely to overestimate it. The results are presented in Table 1.

Table 1

Subgroup analysis for the US

\begin{tabular}{|c|c|c|c|c|c|c|c|c|c|c|c|}
\hline & \multicolumn{3}{|c|}{ Marital Status } & \multicolumn{3}{|c|}{ Educational Level } & \multicolumn{5}{|l|}{ Ethnicity } \\
\hline & Single & Married & $\begin{array}{l}p- \\
\text { value }\end{array}$ & High & Low & $\begin{array}{l}p- \\
\text { value }\end{array}$ & Hispanic & White & Black & Asian & $\begin{array}{l}p- \\
\text { value }\end{array}$ \\
\hline $\begin{array}{l}\text { Normal but } \\
\text { consider } \\
\text { themselves } \\
\text { to be } \\
\text { overweight }\end{array}$ & $\begin{array}{l}7.7 \% \\
(5 / 62)\end{array}$ & $\begin{array}{l}14.8 \% \\
(30 / 203)\end{array}$ & $0.011 *$ & $\begin{array}{l}19.2 \% \\
(20 / 104)\end{array}$ & $\begin{array}{l}8.7 \% \\
(15 / 172)\end{array}$ & 0.140 & $\begin{array}{l}4.3 \% \\
(2 / 47)\end{array}$ & $\begin{array}{l}10.7 \% \\
(9 / 84)\end{array}$ & $\begin{array}{l}3.8 \% \\
(2 / 53)\end{array}$ & $\begin{array}{l}21.4 \% \\
(15 / 70)\end{array}$ & $0.005^{\star}$ \\
\hline $\begin{array}{l}\text { Overweight } \\
\text { but consider } \\
\text { themselves } \\
\text { to be } \\
\text { normal or } \\
\text { underweight }\end{array}$ & $\begin{array}{l}42.9 \% \\
(15 / 35)\end{array}$ & $\begin{array}{l}46.2 \% \\
(80 / 173)\end{array}$ & 0.325 & $\begin{array}{l}41.3 \% \\
(26 / 63)\end{array}$ & $\begin{array}{l}48.6 \% \\
(72 / 146)\end{array}$ & 0.714 & $\begin{array}{l}50.8 \% \\
(32 / 63)\end{array}$ & $\begin{array}{l}41.3 \% \\
(26 / 63)\end{array}$ & $\begin{array}{l}65.6 \% \\
(21 / 32)\end{array}$ & $\begin{array}{l}38.9 \% \\
(14 / 36)\end{array}$ & 0.089 \\
\hline $\begin{array}{l}\text { Obese but } \\
\text { consider } \\
\text { themselves } \\
\text { to be } \\
\text { normal or } \\
\text { underweight }\end{array}$ & $\begin{array}{l}16.7 \% \\
(13 / 78)\end{array}$ & $\begin{array}{l}10.2 \% \\
(29 / 285)\end{array}$ & 0.251 & $\begin{array}{l}7.5 \% \\
(5 / 67)\end{array}$ & $\begin{array}{l}12.4 \% \\
(37 / 298)\end{array}$ & 0.112 & $\begin{array}{l}11.8 \% \\
(11 / 93)\end{array}$ & $\begin{array}{l}9.3 \% \\
(10 / 107)\end{array}$ & $\begin{array}{l}16.2 \% \\
(17 / 105)\end{array}$ & $\begin{array}{l}8.7 \% \\
(2 / 23)\end{array}$ & 0.449 \\
\hline
\end{tabular}

\section{Subgroup Analysis for Korea}

For young Korean women, marital status, educational level, and occupation did not significantly affect their self-body image. There were items with statistically significant differences due to the large number of subjects, but the difference in absolute values was not significant. The results are shown in Table 2. 
Table 2

Subgroup analysis for Korea

\begin{tabular}{|c|c|c|c|c|c|c|c|c|c|}
\hline & \multicolumn{3}{|c|}{ Marital Status } & \multicolumn{3}{|c|}{ Educational Level } & \multicolumn{3}{|l|}{ Occupation } \\
\hline & Single & Married & $\begin{array}{l}p- \\
\text { value }\end{array}$ & High & Low & $\begin{array}{l}p- \\
\text { value }\end{array}$ & Hispanic & Asian & $\begin{array}{l}p \text { - } \\
\text { value }\end{array}$ \\
\hline \multirow{2}{*}{$\begin{array}{l}\text { Normal but consider } \\
\text { themselves to be } \\
\text { overweight }\end{array}$} & $34.4 \%$ & $36.5 \%$ & \multirow[t]{2}{*}{$0.012^{*}$} & $34.2 \%$ & $40.1 \%$ & \multirow[t]{2}{*}{0.334} & $32.6 \%$ & $37.3 \%$ & \multirow[t]{2}{*}{0.062} \\
\hline & $(279 / 812)$ & $(435 / 1193)$ & & $(454 / 1327)$ & $(245 / 611)$ & & $(159 / 488)$ & $(540 / 1449)$ & \\
\hline \multirow{2}{*}{$\begin{array}{l}\text { Overweight but } \\
\text { consider themselves to } \\
\text { be normal or } \\
\text { underweight }\end{array}$} & $1.40 \%$ & $3.40 \%$ & \multirow[t]{2}{*}{0.799} & $2.0 \%$ & $2.4 \%$ & \multirow[t]{2}{*}{0.241} & $1.20 \%$ & $2.40 \%$ & \multirow[t]{2}{*}{0.528} \\
\hline & $(2 / 140)$ & $(10 / 294)$ & & $(5 / 250)$ & $(4 / 169)$ & & $(1 / 81)$ & $(8 / 338)$ & \\
\hline \multirow{2}{*}{$\begin{array}{l}\text { Obese but consider } \\
\text { themselves to be } \\
\text { normal or underweight }\end{array}$} & $0.0 \%$ & $1.10 \%$ & \multirow[t]{2}{*}{0.316} & $0 \%$ & $1.40 \%$ & \multirow[t]{2}{*}{0.433} & $0.0 \%$ & $0.90 \%$ & \multirow[t]{2}{*}{0.624} \\
\hline & $(0 / 55)$ & $(1 / 90)$ & & $(0 / 70)$ & $(1 / 70)$ & & $(0 / 27)$ & $(1 / 113)$ & \\
\hline
\end{tabular}

\section{Discussion}

The significant results of this study are summarized as follows: 1) The percentage of overweight or obese young women in 1999-2000 was about $60 \%$ in the US and about $20 \%$ in Korea, which has not changed much over the past 20 years. 2) Twenty years ago, the proportion of young women who overestimated their weight in the US was $30.3 \%$, which steadily declined afterwards. In Korea, this percentage was $25.8 \%$, before rising to more than $40 \%$ in 2008, decreasing since. 3) Of the overweight women, $32.6 \%$ in the US and $15.7 \%$ in Korea underestimated their weight 20 years ago, but since then, the percentage has gradually increased in the US and declined in Korea. 4) Body image perception differed according to marital status and race in the US, and according to marital status in Korea.

Obesity is a serious health issue in the modern society, causing various diseases, such as diabetes, high blood pressure, myocardial infarction, stroke, cancer, fatty liver, cholelithiasis, osteoarthritis, and gout [14]. It is also associated with mental and social difficulties, such as low self-esteem, anxiety, depression, interpersonal disorders, poor quality of life, and stress $[5,6,15]$. According to OECD statistics [16], the percentage of obese population in the US increased by $6 \%$ between 2000 and 2016, from 62.0-67.9\%, while in Korea it decreased slightly from $28.0 \%$ in 2001 to $27.4 \%$ in 2018 . In this study regarding only young women, the obesity percentage was slightly lower than that of the total population. However, the percentage of obese population in the US is about $40 \%$ higher than in Korea.

The change in the percentage of women who overestimate their own weight (having a normal weight but perceiving themselves as overweight or obese) is interesting. Just 20 years ago, it was higher in the US than in Korea. However, as body image perception has changed positively in the States, the percentage of obese population remained almost unchanged, but the overestimating percentage gradually decreased. In Korea, however, this percentage continued to increase until 2010 , approximately $20 \%$ higher than in the US. At that time, women's participation in the society was very active in Korea, but the standards for women's beauty were very narrow [7]. It is believed that the recent appearance of unrealistically skinny women in Korean mass media also affected the changed standards. Furthermore, Lee [17] suggested that the use of social network services, which rapidly increased with the spread of smartphones, also played a role, with reports indicating that young women who use these services have severe body image recognition problems and distortions [18]. Fortunately, the percentage has declined in Korea since then, but the gap with the US is still large. It is difficult to specify the exact reason for the decline in the last 10 years, but we believe it was influenced by the steadily increasing feminist movement in Korea, as well [19].

The percentage change of women in the two countries who underestimate their body image (being obese or overweight but considering themselves as normal or underweight) is the opposite of the overestimating case. In the past 20 years, in the US, the percentage has gradually increased, and in Korea it has been decreasing. The underestimating percentage in the US was surprising. As of 2017 , about $50 \%$ of overweight and $10 \%$ of obese women perceived themselves as normal or underweight. During the same period, those percentages in Korea were approximately $3 \%$ and $1 \%$, respectively. It is unclear why so many women in the US underestimate their weight. As explained in the Introduction, the stronger culture of individualism in Western society may be a factor. Another possibility is the high rate of obesity in the country. As people often see obese individuals around them, they lose a sense of their normal weight and perceive obesity as a normal weight. Conversely, in a society where the obesity rate is low and there are many skinny people, such as in Korea, people tend to overestimate their own weight.

Various factors affect the perception of body image. In this study, we also investigated differences in body image perception according to factors, such as marital status, educational level, ethnicity, and occupation. Regarding marital status, in both the US and Korea, married 
women have a higher rate of overestimating their weight than single ones. Studies have shown that single women are more likely to overestimate their weight, and we also predicted that this group would be more interested in appearance and weight than married women, thus being more likely to overestimate, but the actual result was the opposite. In other words, married women pay more attention to body image than single ones. Previous studies have shown that women with high education and professions often overestimate, but this research did not find any relevance. No clear reason for these differences was identified. In the US, the rate of overestimation by race was significantly different. Asian women had the highest rate of overestimation, followed by White, Hispanic, and Blacks, respectively. Conversely, the rate of obesity in the US is lowest in Asians and highest in the Hispanic and Black groups. In the past, studies have shown that the overestimation rate of whites was higher than that of other races $[7,12,13,20]$. We believe that these differences among studies are due to the different research methods and timing $[7,21]$. Studies have also indicated that negative psychology (self-loss, avoidance of popularity, depression, suicidal thoughts, etc.) or abnormal behaviors (excessive diet, binge eating, etc.) are associated with body image perception [5, 6, 15, 22], but this research was unable to analyze these effects due to lack of data.

\section{Conclusion}

Young women in the US nowadays tend to underestimate their weight compared to those in the past, whereas in Korea, they often overestimate their weight. Overestimating can lead to issues, such as excessive stress and an unnecessary diet, while underestimation can lead to obesity. Therefore, it is necessary to have an accurate body image perception.

\section{Limitation}

In the NHANES dataset, only $5.8 \%$ were excluded due to missing data, but in the KNHANES dataset, $41.3 \%$ were excluded, suggesting a possibility of selection bias.

\section{Abbreviations}

\section{KNHANES}

the Korean National Health and Nutrition Examination Survey

NHANES

the National Health and Nutrition Examination Survey (, from 1999

\section{Declarations}

\section{Acknowledgements}

Nothing to mention

\section{Authors' contributions}

YSK, JKK, and JHC were involved in this study from the inception to design, acquisition, analysis, and interpretation of data and drafting of the manuscript. All authors agreed to submit to the current journal; gave final approval of the version to be published; and agree to be accountable for all aspects of the work. All authors read and approved the final manuscript.

\section{Funding}

No fund was accepted from any organization for this research.

\section{Availability of data and materials}

All datasets are available on the following website:

KNHANES: https://knhanes.kdca.go.kr/knhanes/main.do

NHANES: https://www.cdc.gov/nchs/nhanes/index.htm

\section{Ethics approval and consent to participate}

The World Medical Association Declaration of Helsinki guidance was followed in designing and conducting this study. However, it was not subject to ethical review as researchers used public data from the KNHANES in Korea and the NHANES in the US. 


\section{Consent for publication}

Not applicable for this section.

\section{Competing interests}

We declare that there is no competing interest with anyone else.

\section{References}

1. Jang HS, Kim TR. The Effect of Mass Media on Body Perception and State Esteem of Body Image. Studies on Korean Youth. 2006;17(2):57-83.

2. Seo MJ, Son CN. Effects of Rational Emotive Behavior Therapy (REBT) on Maladaptive Perfectionism, Body Dissatisfaction, and Implicit Attitude toward Body Image in College Students. THE KOREAN JOURNAL OF HEALTH PSYCHOLOGY. 2015;20(3):547-66.

3. Ju SJ, Cho SS. The Verification of Mediating Effects of Internet Addiction in Relations Body Images and School Maladjustment of Youth: Focusing on the Comparison of the Groups According to Household Characteristics. Journal of Youth Welfare. 2013;15(2):33-59.

4. Sarwer DB, Polonsky HM. Body Image and Body Contouring Procedures. Aesthetic surgery journal. 2016;36(9):1039-47

5. Alipour B, Abbasalizad Farhangi M, Dehghan P, Alipour M. Body image perception and its association with body mass index and nutrient intakes among female college students aged 18-35 years from Tabriz, Iran. Eating and weight disorders: EWD. 2015;20(4):465-71.

6. Hyun H, Lee H, Ro Y, Gray HL, Song K. Body image, weight management behavior, nutritional knowledge and dietary habits in high school boys in Korea and China. Asia Pacific journal of clinical nutrition. 2017;26(5):923-30.

7. Kim SW. Incompatibility between Objective and Subjective Body Shapes: A Case in Korea. The Statictical Review. 2017;22(4):92-120.

8. Sand AS, Emaus N, Lian O. Overweight and obesity in young adult women: A matter of health or appearance? The Troms $\emptyset$ study: Fit futures. International journal of qualitative studies on health and well-being. 2015;10:29026.

9. Markus HR, Kitayama S. Culture and the self: Implications for cognition, emotion, and motivation. Psychological Review. 1991;98(2):224-53.

10. Singelis TM. The Measurement of Independent and Interdependent Self-Construals. 1994;20(5):580-91.

11. Wang CL, Bristol T, Mowen JC, Chakraborty G. Alternative Modes of Self-Construal: Dimensions of Connectedness-Separateness and Advertising Appeals to the Cultural and Gender-Specific Self. Journal of Consumer Psychology. 2000;9(2):107-15.

12. Bhuiyan AR, Gustat J, Srinivasan SR, Berenson GS. Differences in body shape representations among young adults from a biracial (Black-White), semirural community: the Bogalusa Heart Study. Am J Epidemiol. 2003;158(8):792-7.

13. Rand CS, Resnick JL. The "good enough" body size as judged by people of varying age and weight. Obesity research. 2000;8(4):309-16.

14. Park HS, Cho HJ, Kim YS, Kim CJ. The diseases associated with obesity in Korean adults. Journal of the Korean Academy of Family Medicine. 1992;13(4):344-53.

15. Cabioglu MT, Ergene N, Tan U. Electroacupuncture treatment of obesity with psychological symptoms. The International journal of neuroscience. 2007;117(5):579-90.

16. OECD. Rate of Overweight or Obesity. https://stats.oecd.org/. Accessed 16 Dec 2020.

17. Hogue JV, Mills JS. The effects of active social media engagement with peers on body image in young women. Body Image. 2019;28:15.

18. Alipour B, Abbasalizad Farhangi M, Dehghan P, Alipour M. Body image perception and its association with body mass index and nutrient intakes among female college students aged 18-35 years from Tabriz, Iran. Eat Weight Disord. 2015;20(4):465-471. doi:10.1007/s40519-015-0184-1

19. Gong MH. The origin and history of feminism. Women of Busan Women and Development Institute. 2019;61:6-9.

20. Friedman MA, Brownell KD. Psychological correlates of obesity: moving to the next research generation. Psychological bulletin. 1995;117(1):3-20.

21. Wardle J, Haase AM, Steptoe A. Body image and weight control in young adults: international comparisons in university students from 22 countries. International journal of obesity (2005). 2006;30(4):644 - 51.

22. Liechty JM. Body image distortion and three types of weight loss behaviors among nonoverweight girls in the United States. The Journal of adolescent health: official publication of the Society for Adolescent Medicine. 2010;47(2):176-82.

\section{Figures}




\begin{tabular}{|c|c|c|c|c|c|}
\hline \multicolumn{2}{|c|}{ NHANES } & \multicolumn{2}{|c|}{ NHANES } & \multicolumn{2}{|c|}{ NHANES } \\
\hline Year & Enrollee (n) & Year & Enrollee (n) & Year & Enrollee (n) \\
\hline $1999-2000$ & 9,965 & $1999-2000$ & 1,020 & $1999-2000$ & 934 \\
\hline $2001-2002$ & 11,039 & $2001-2002$ & 1,156 & 2001-2002 & 1,052 \\
\hline 2003-2004 & 10,122 & 2003-2004 & 968 & 2003-2004 & 908 \\
\hline $2005-2006$ & 10,348 & $2005-2006$ & 1,139 & $2005-2006$ & 1,083 \\
\hline $2007-2008$ & 10,149 & $2007-2008$ & 1,011 & $2007-2008$ & 973 \\
\hline 2009-2010 & 10,537 & $2009-2010$ & 1,165 & 2009-2010 & 1,135 \\
\hline $2011-2012$ & 9,756 & $2011-2012$ & 1,020 & $2011-2012$ & 969 \\
\hline $2013-2014$ & 10,175 & 2013-2014 & 1,062 & 2013-2014 & 1,017 \\
\hline $2015-2016$ & 9,971 & $2015-2016$ & 1,069 & $2015-2016$ & 1,014 \\
\hline $2017-2018$ & 9,254 & $2017-2018$ & 926 & $2017-2018$ & 843 \\
\hline total & 101,316 & total & 10,536 & total & 9,928 \\
\hline \multicolumn{2}{|c|}{ KNHANES } & \multicolumn{2}{|c|}{ KNHANES } & \multicolumn{2}{|c|}{ KNHANES } \\
\hline Year & Enrollee $(n)$ & Year & Enrollee (n) & Year & Enrollee $(n)$ \\
\hline 2001 & 37,865 & 2001 & 6,670 & 2001 & 1,551 \\
\hline 2005 & 34,145 & 2005 & 5,562 & 2005 & 1,183 \\
\hline $2007-2009$ & 24,871 & $2007-2009$ & 3,661 & $2007-2009$ & 3,415 \\
\hline $2010-2012$ & 25,534 & $2010-2012$ & 3,538 & $2010-2012$ & 3,263 \\
\hline $2013-2015$ & 22,948 & 2013-2015 & 2,983 & 2013-2015 & 2,676 \\
\hline $2016-2018$ & 24,269 & $2016-2018$ & 3,053 & $2016-2018$ & 2,861 \\
\hline total & 169,632 & total & 25,467 & total & 14,949 \\
\hline
\end{tabular}

Figure 1

Selection process 


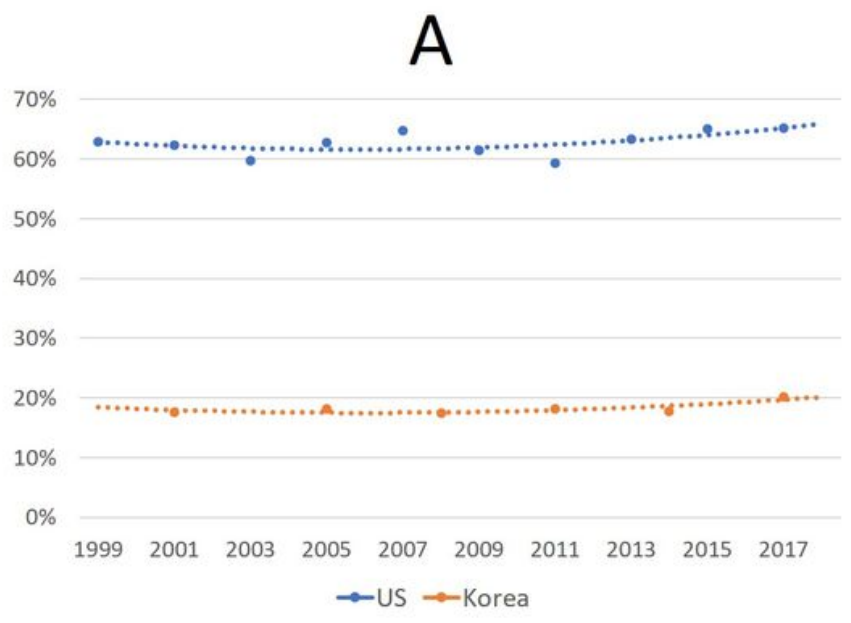

\section{C}

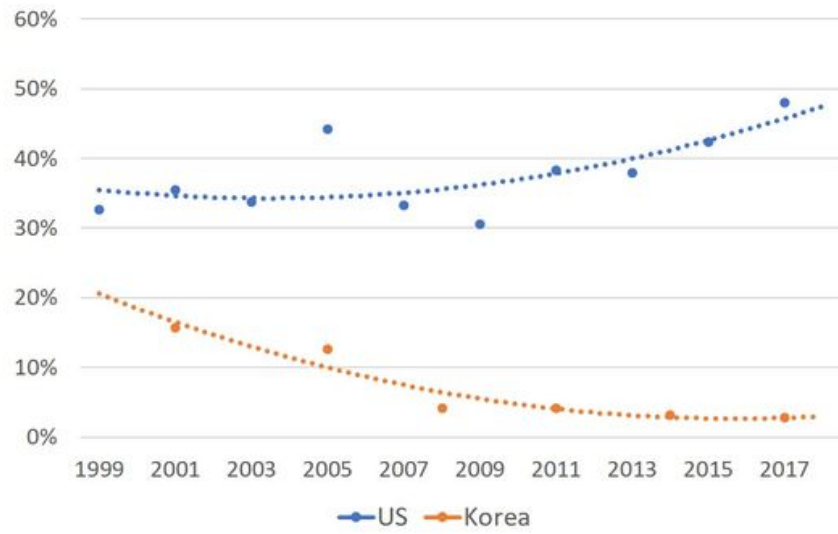

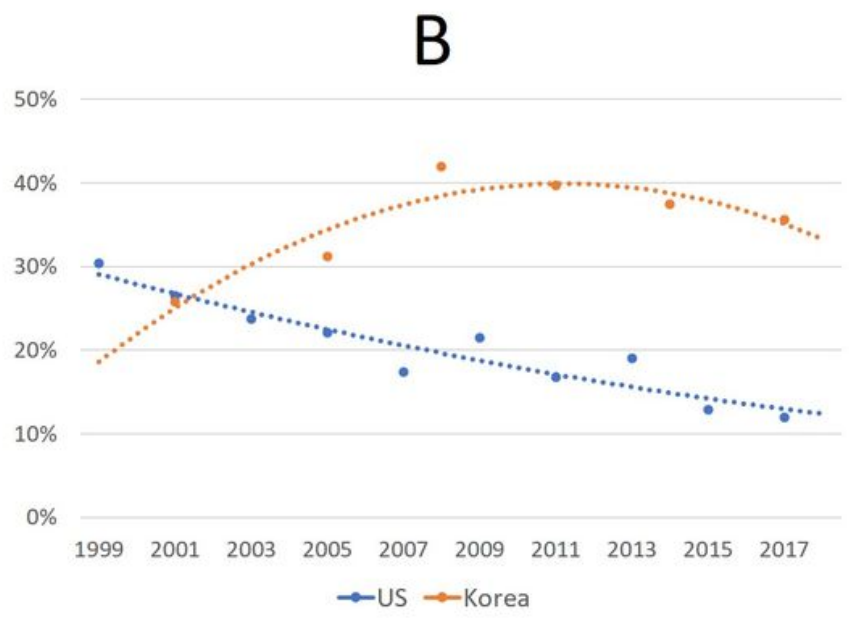

D

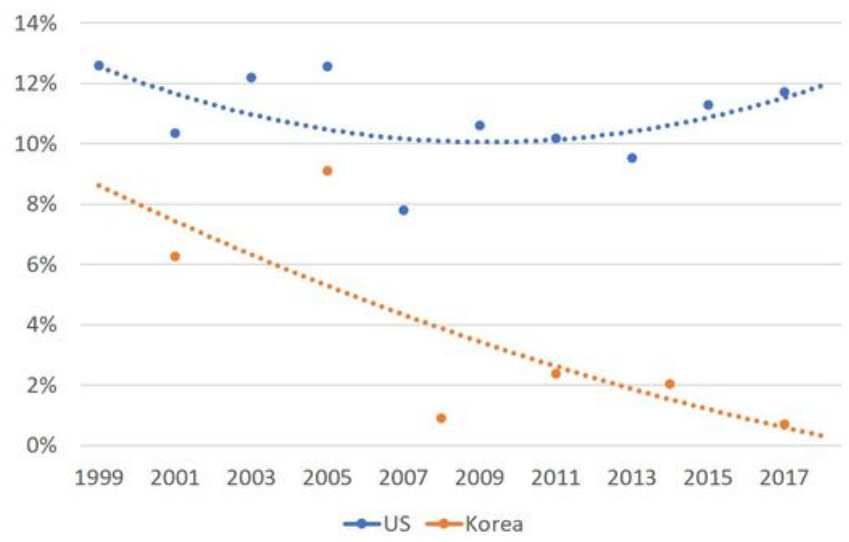

\section{Figure 2}

\section{Comparison of body image perception in the US and Korea}

A) Percentage of young women who are overweight and obese according to the BMI classification. B) Percentage of young women in the normal BMI range who consider themselves as overweight. C) Percentage of overweight young women who consider themselves as normal or underweight. D) Percentage of obese young women who consider themselves as normal or underweight.

\section{Supplementary Files}

This is a list of supplementary files associated with this preprint. Click to download.

- Supplement.docx 